\title{
Eugenol-hyperactivated nymphs of Triatoma infestans become intoxicated faster than non-hyperactivated nymphs when exposed to a permethrin-treated surface
}

\author{
Mercedes María Noel Reynoso, Alejandro Lucia, Eduardo Nicolás Zerba and Raúl Adolfo Alzogaray*
}

\begin{abstract}
Background: Eugenol is a botanical monoterpene that hyperactivates the blood-sucking bug Triatoma infestans, and permethrin is a pyrethroid with a strong triatomicide effect. In the present work, we tested the hypothesis that eugenol-hyperactivated nymphs of $T$. infestans pick up more insecticide, and then become intoxicated faster, than non-hyperactivated nymphs when exposed to a permethrin-treated surface.

Results: Values of knockdown time 50\% (KT50) for third-instar T. infestans exposed to a paper impregnated with permethrin were obtained under the following situations: (a.i.) immediately after topical application of eugenol (KT50: $66.75 \mathrm{~min}$ for acetone pre-treated controls, and $46.27 \mathrm{~min}$ for eugenol pre-treated nymphs); (a.ii.) $30 \mathrm{~min}$ after topical application of eugenol (KT50: $66.79 \mathrm{~min}$ for controls, and $66.79 \mathrm{~min}$ for eugenol pre-treated nymphs); (b) simultaneously with exposure to eugenol vapors (KT50: 51.90 min for controls, and 39.5 min for nymphs exposed to an eugenol-treated filter paper); and (c) immediately after an injection of eugenol (on average, controls were knocked down after $63.00 \mathrm{~min}$, whereas nymphs injected with eugenol were knocked down after $65.30 \mathrm{~min}$ ). In other experimental series, the distance traveled (DT) by nymphs exposed to eugenol was quantified in the same situations previously described, but without exposure to permethrin. In (a.i.), the DT in interval 0-30 min after topical application of eugenol was 487.00 (control) and 1127.50 (eugenol) cm; in (a.ii.), the DT in the interval 31-60 min after topical application was 336.75 (control) and 256.75 (eugenol) cm; in (b), DT was 939.08 (control) and 1048.53 (eugenol) cm; and in (c), it was 589.20 (control) and 700.00 (eugenol) cm. The KT50 values for permethrin decreased significantly in situations (a.i.) and (b), and eugenol only produced a significant hyperactivity in the same situations. Finally, the amount of permethrin picked up by non-hyperactivated and hyperactivated nymphs exposed to a film of permethrin was quantified by gas chromatography. Non-hyperactivated nymphs picked up $0.34 \mathrm{\mu g} /$ insect of permethrin, while hyperactivated nymphs picked up $0.65 \mu \mathrm{g} /$ insect.
\end{abstract}

Conclusion: Results support the hypothesis that eugenol-hyperactivated nymphs of $T$. infestans pick up more insecticide, and then become intoxicated faster, than non-hyperactivated nymphs when exposed to a permethrin-treated surface.

Keywords: Triatoma infestans, Triatominae, Eugenol, Permethrin, Hyperactivity, Increased intoxication, Insecticide pick up, Chagas disease

* Correspondence: ralzogaray@hotmail.com

UNIDEF-CITEDEF-CONICET- CIPEIN, Juan B. de La Salle 4397, (1603) Villa

Martelli, Buenos Aires, Argentina

(c) The Author(s). 2018 Open Access This article is distributed under the terms of the Creative Commons Attribution 4.0 International License (http://creativecommons.org/licenses/by/4.0/), which permits unrestricted use, distribution, and reproduction in any medium, provided you give appropriate credit to the original author(s) and the source, provide a link to the Creative Commons license, and indicate if changes were made. The Creative Commons Public Domain Dedication waiver (http://creativecommons.org/publicdomain/zero/1.0/) applies to the data made available in this article, unless otherwise stated. 


\section{Background}

Eugenol is a botanical monoterpene present in the essential oils of clove, cinnamon, nutmeg, basil and other plants [1]. Its very low toxicity in mammals allows it to be used in odontology (for surgical dressings, temporary fillings, pulp capping agents and cavity liners), as a food flavoring and in perfumes [2]. It also shows insecticidal and repellent activities in several insect species [3-7]. An almost unexplored sublethal effect of monoterpenes consists in the modification of insect locomotor activity $[8,9]$. For example, eugenol hyperactivates nymphs of the blood-sucking bug Triatoma infestans, vector of Trypanosoma cruzi, the causal agent of Chagas disease in Latin America [8]. The primary sites of action of the vast majority of insecticidal monoterpenes are unknown, but there is evidence suggesting that eugenol is a ligand of the octopamine receptor of the insects' nervous system [10].

When an organism is exposed to a mixture of two or more substances, their biological activity can be modified by the presence of the other compound. As a consequence of their interaction, the effect of the resulting combination can be higher or lower than the addition of the effects of each substance alone (synergism and antagonism, respectively) [11]. Both types of interactions have been observed in binary combinations of monoterpenes [12-15].

The classical concept of toxicological interactions considers the processes of absorption, distribution, metabolism, reaching sites of action and excretion of the components of the mixtures [16]. Some of these processes have been suggested as responsible for the toxicological interactions observed between monoterpenes [17-19]. In the cabbage looper, Trichoplusia ni, topical application of a mixture of $p$-cymene and thymol has a synergic effect since the first substance increases cuticle penetration, increasing the toxicity of the second substance $[14,20]$.

Other interactions involve changes in insect behavior. Incorporation of volatile host-plants increased the attraction of the boll weevil, Anthonomus grandis, and the palm weevil, Rhynchophorus ferrugineus, to their respective aggregation pheromones [21, 22]. In these cases, the behavioral response of insects exposed to a mixture of volatile substances was greater than the response to the components applied individually. This type of interaction has been named "behavioral synergism" [23].

The behavior of an insect can modify its exposure to a surface treated with insecticide. For example, hyperactive larvae of the tobacco budworm, Heliothis virescens picked up more permethrin from a treated surface than less active larvae of the same species [24].

Considering the information summarized above, the aim of this work was to test the hypothesis that eugenol-hyperactivated nymphs of $T$. infestans become intoxicated faster than non-hyperactivated nymphs when exposed to a permethrin-treated surface.

\section{Methods \\ Biological material}

We used third-instar nymphs of $T$. infestans, 1-14 days-old and starved after molt, from a colony at the Centro de Investigaciones de Plagas e Insecticidas (UNIDEF-CITEDEF-CONICET-CIPEIN, Buenos Aires, Argentina). This colony was established from a sample of insects donated by the Instituto Nacional de Parasitología "Dr. Mario Fatala Chaben" (Buenos Aires, Argentina). Insects were reared at a temperature of $25 \pm$ $2{ }^{\circ} \mathrm{C}, 60-90 \%$ relative humidity and under a $12: 12 \mathrm{~h}$ (L:D) photoperiod. Insects were fed on pigeon blood once per week according to a protocol approved by the Institutional Animal Care and Use Committee of CIPEIN (IACUC/CICUAL 1531/13).

\section{Chemicals}

Permethrin $(94.5 \%)$ was provided by Chemotecnica S.A. (C. Spegazzini, Buenos Aires, Argentina), eugenol (99\%) was purchased from Sigma-Aldrich (Buenos Aires, Argentina), acetone (technical grade) from Merck (Darmstadt, Germany) and silicone oil (556 cosmetic grade fluid) from Daltosur S.R.L. (Buenos Aires, Argentina).

We used eugenol due to its reported effect on the locomotor activity of $T$. infestans nymphs [8]. On the other hand, we chose permethrin because, in addition to its proved lethal effect on $T$. infestans [25], we found that the concentrations needed for our toxicity assays did not modify the locomotor activity of the nymphs. This was a key requirement, as in order to test our hypothesis we needed only eugenol to produce hyperactivity.

\section{Bioassays of toxicity \\ Topical application of eugenol followed by exposure to a permethrin-treated surface}

A disc of filter paper $11 \mathrm{~cm}$ in diameter (102 FAST, Hangzhou Xinxing Paper Industry \& Co. Ltd., Funyang, China) was impregnated with $0.5 \mathrm{ml}$ permethrin dissolved in an acetone:silicone (1:1) solution (1840 mg/ $\mathrm{m}^{2}$ ). The solvent was left to evaporate for an hour and then a glass ring $(4 \mathrm{~cm}$ high and $10 \mathrm{~cm}$ in diameter) was placed over the paper disc.

Using a microsyringe (Hamilton, Reno, NE), $1 \mu \mathrm{l}$ of eugenol dissolved in acetone was dropped onto the dorsal side of the abdomen of ten nymphs $(0.1 \mu \mathrm{g} /$ insect). They were then placed on the disc of filter paper impregnated with permethrin (a.i) immediately or (a.ii) 30 min after the topical application of eugenol. As controls, ten nymphs were treated with acetone alone in each case. The number of knockdown individuals was registered every $5 \mathrm{~min}$. A nymph was considered knocked down if it remained in the same place for $30 \mathrm{~s}$ after being gently touched with a soft pair of tweezers (controls walked away immediately after being touched). Three 
independent replicates were carried out and each included a group of ten nymphs exposed to a filter paper impregnated only with the solvent. Knockdown time $50 \%$ (KT50) values were calculated with the results.

\section{Simultaneous exposure to eugenol vapors and $a$ permethrin-treated surface}

The source of vapors was a piece of rectangular filter paper impregnated with eugenol $(3.0 \times 29.1 \mathrm{~cm})($ Fig. 1) One of the longer sides of the rectangle had six square lapels $(0.5 \times 0.5 \mathrm{~cm})$ separated by $4.3 \mathrm{~cm}$, that were turned up at a $90^{\circ}$ angle. The surface of the rectangle was treated with $0.5 \mathrm{ml}$ of eugenol dissolved in acetone $\left(33 \mu \mathrm{g} / \mathrm{cm}^{2}\right)$. Once the solvent had evaporated, the inner side of the glass ring was lined with the paper rectangle, leaving the lapels to hang over the upper side of the ring. Thus, when the glass ring was placed over the circle of filter paper impregnated with permethrin, the bottom side of the paper rectangle hung $1 \mathrm{~cm}$ above the filter paper and was out of reach from the ten nymphs that were subsequently placed inside the ring. Finally, the upper side of the ring was covered with a glass square $(10 \times 10 \mathrm{~cm})$ to create a micro-atmosphere with eugenol. Four independent replicates were carried out and each included a group of ten nymphs exposed to a piece of rectangular filter paper treated with acetone alone.
Injection of eugenol followed by exposure to a permethrin-

\section{treated surface}

The upper side of a slide was covered by double-sided adhesive tape and a nymph was placed in a supine position and attached dorsally. Using a microsyringe and a binocular Nikon SMZ-10 10× magnifying glass (Tokyo, Japan), $0.2 \mu \mathrm{l}$ of eugenol dissolved in acetone was injected into the nymph (2 ng/insect). The injection was performed in the left pleura of the first abdominal segment using a microsyringe (Hamilton, Reno, NE, USA). The nymph was then gently unstuck from the adhesive tape and placed in the center of a permethrin-impregnated filter paper disc. A nymph injected with acetone alone was used as control. As the immobilization and injection of the nymphs took longer than a topical application, in this series of experiments nymphs were individually exposed to a permethrin-treated filter paper. The time until each nymph was knocked down was registered. Each treatment was independently repeated ten times.

\section{Bioassays of locomotor activity}

Experiments were carried out inside a wooden box coated with melamine $(1.0 \times 0.5 \times 0.5 \mathrm{~m})$. The experimental arena was a filter paper disc $(11 \mathrm{~cm}$ in diameter $)$ (102 FAST; Hangzhou Xinxing Paper Industry \& Co. Ltd.) placed on the floor of the box. A glass ring $(4 \mathrm{~cm}$ high and $10 \mathrm{~cm}$ in diameter) was placed over the paper disc. A video camera was located $20 \mathrm{~cm}$ above the

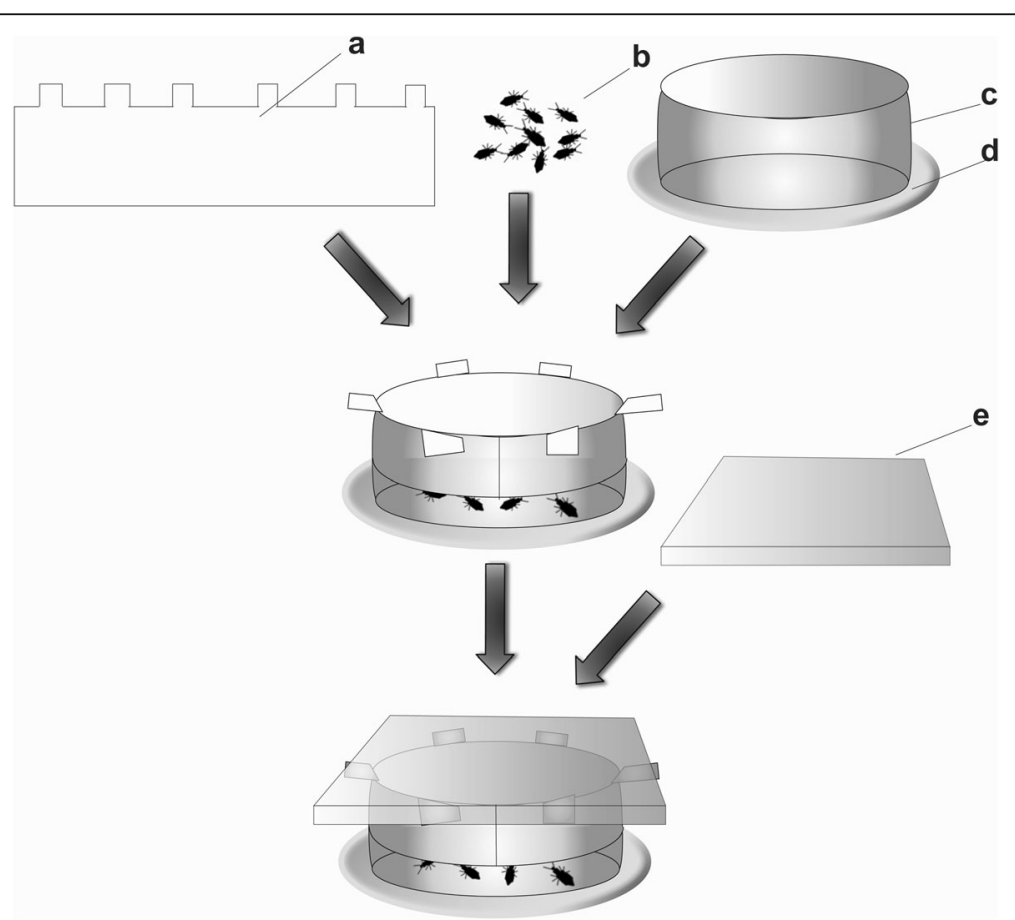

Fig. 1 Experimental arena used for simultaneous exposure of T. infestans nymphs to eugenol (vapors) and permethrin (contact): eugenol-impregnated piece of rectangular filter paper with six square lapels (a), T. infestans nymphs (b), glass ring (c), filter paper impregnated with permethrin (d), and glass square (e) 
experimental arena (HD Webcam C525, Logitech, Lausanne, Switzerland) and connected to a personal computer. The camera had a resolution of $640 \times 480$ pixels with an acquisition and image processing speed of 30 frames/second. Lighting was provided by a cold light bulb (22 watts; Luxa, Shanghai, China) placed in the center of the top of the box.

A nymph was placed on the center of the filter paper and its movement was registered for $60 \mathrm{~min}$. This experimental time allowed determining the duration of the effect of eugenol on locomotor activity and observing the way nymphs behaved once the hyperactive effect disappeared.

The video was analyzed using EthoVision XT 10.0 software [26]. This program quantifies the distance an insect moves expressed in $\mathrm{cm}$.

The four experimental series described below (a'-d') were carried out using the same doses and concentrations of eugenol and permethrin as used in the toxicity bioassays. After testing that there were no variations in nymph locomotor activity between 11 am and $15 \mathrm{pm}$, trials were always performed within that time frame.

(a') Topical application of eugenol. Three independent replicates were performed, each including a nymph treated with acetone alone and another one treated with $0.1 \mu \mathrm{g}$ eugenol/insect;

(b') Exposure to eugenol vapors. Six independent replicates were carried out, each including a nymph exposed to a piece of rectangular filter paper treated with acetone alone and another one exposed to a piece of rectangular filter paper impregnated with a solution of eugenol in acetone $\left(33 \mu \mathrm{g} / \mathrm{cm}^{2}\right)$;

(c') Eugenol injection. One nymph was injected with acetone alone and another with $2 \mathrm{ng}$ eugenol/insect. Each treatment was independently repeated ten times; (d') Exposure to a paper filter disc impregnated with permethrin. Three independent replicates were carried out, each including a nymph exposed to a disc of filter paper treated with solvent alone and another one exposed to a disc of filter paper treated with permethrin $\left(1840 \mathrm{mg} / \mathrm{m}^{2}\right)$.

Each of these four experimental series included one or two untreated control groups as follows: in series (a'), nymphs with no topical application; in (b'), nymphs exposed to an untreated piece of rectangular filter paper; in (c'), a group of nymphs pricked with the microsyringe needle but not injected with any substance, and a group of non-pricked nymphs; and in (d'), nymphs exposed to an untreated filter paper disc.

\section{Extraction of the permethrin picked up by the nymphs} The procedure published by Pennell et al. [27] was adopted in this study with major modifications. Five hundred microliters of permethrin in acetone $(0.035 \mathrm{~g} /$ $\mathrm{ml}$ ) were applied on a circle of filter paper to obtain a concentration of $1840 \mathrm{mg} / \mathrm{m}^{2}$. After solvent evaporation, the filter paper was placed on a horizontal surface and a glass ring was placed over it. Then, a group of ten nymphs topically pre-treated with $0.1 \mu \mathrm{g} /$ insect of eugenol in acetone was placed on the permethrin-treated filter paper. After $10 \mathrm{~min}$, the insects were transferred to a glass vial $(2 \mathrm{ml})$ and fully immersed in $0.5 \mathrm{ml}$ of acetone. The glass vial was gently shaken for $2 \mathrm{~min}$ after which the insects were discarded. Finally, an additional volume of acetone was added to the vial to complete $1 \mathrm{ml}$.

\section{GC-MS analysis for determining the quantity of permethrin picked up}

The analysis of permethrin was performed using a GC-2010 instrument coupled with a QP2010 mass spectrometer detector (Shimadzu, Kyoto, Japan) in the electron impact mode $(70 \mathrm{eV})$. Samples were analyzed following the methodology used by Pinheiro et al. [28]. An apolar GC capillary column DB-5 $(30 \mathrm{~m} \times 0.25 \mathrm{~mm}$ i.d. and $0.25 \mu \mathrm{m}$ coating thickness; J\&W Scientific, Folsom, CA, USA) was used. The GC column temperature was maintained at $60{ }^{\circ} \mathrm{C}$ for $1 \mathrm{~min}$, then programmed to increase from 60 to $150{ }^{\circ} \mathrm{C}$ at a rate of $20{ }^{\circ} \mathrm{C} / \mathrm{min}$, held for $4 \mathrm{~min}$ and then increased to $290{ }^{\circ} \mathrm{C}$ at a rate of $15^{\circ}$ $\mathrm{C} / \mathrm{min}$. This final temperature was held for $5.17 \mathrm{~min}$. The injector was held at $280{ }^{\circ} \mathrm{C}$. Helium (99.99\%) was used as the carrier gas at a $1.2 \mathrm{ml} / \mathrm{min}$ caudal. The detector temperature was $250{ }^{\circ} \mathrm{C}$ and all injections were performed in the splitless mode (sampling time: $2 \mathrm{~min}$ ). The volume of sample injected was $1 \mu \mathrm{l}$. The mass spectrometer scanned mass range $\mathrm{m} / \mathrm{z} 40$ and 400 was used for quantitative determinations of permethrin. For quantitative determination using selective ion monitoring (SIM), permethrin was identified by an ion of mass 183 (retention time: $20.15 \mathrm{~min}$ ). The quantification was performed by calculating the absolute peak areas and a calibration curve was constructed by plotting the peak area of technical permethrin (purity 95.4\%; cis: 52.4) versus permethrin concentration using a linear regression model $\left(R^{2}: 0.99\right)$. With this calibration curve, the amount of permethrin in $1 \mathrm{ml}$ (volume used for the extraction of 10 individuals) was obtained. These values were divided by 10 to obtain the amount of permethrin recovered per nymph (permethrin recovered expressed as $\mu \mathrm{g}$ per insect) of the insects previously treated by topical application of eugenol (treatment) or acetone alone (control).

In summary, the experiment for determining the amount of permethrin picked up by the nymphs consisted of two parts: (a) extraction of the permethrin picked up by the nymphs, and (b) GC-MS analysis for determining the permethrin picked up. This experiment $(a+b)$ was performed five times. Thus, the values of the 
amount of permethrin picked up are representative of five independent experiments. Additionally, as the error was greater than in a routine analysis (by total scan mode), each sample was injected three times and the resulting values were used to calculate the total amount of permethrin. The average variation coefficient obtained for 30 injections by GC-MS was $18.76 \%$.

\section{Statistical analyses}

Values of knockdown time 50\% (KT50) and their corresponding $95 \%$ confidence intervals $(95 \% \mathrm{CI})$ were calculated with the software for correlated data developed by Throne et al. [29]. Differences among KT50 values were consider significant if their $95 \%$ CI did not overlap. The results of the locomotor activity bioassays were analyzed using ANOVA, and those from the permethrin pick up quantification using Student's t-test.

\section{Results}

The toxicity of permethrin applied as a film on filter paper $\left(1840 \mathrm{mg} / \mathrm{m}^{2}\right)$ was quantified in nymphs previously treated topically with eugenol $(0.1 \mu \mathrm{g} /$ insect) (Table 1$)$. When nymphs were exposed to permethrin immediately after the pre-treatment with eugenol, their KT50 (46.27 min) was significantly lower compared to the control group $(66.75 \mathrm{~min})(P<0.05)$. However, when the nymphs were exposed to permethrin $30 \mathrm{~min}$ after the pre-treatment, no significant differences were observed between the KT50 values of the group treated with eugenol (66.79 $\mathrm{min}$ ) and the control group (66.79 $\mathrm{min})$.

The second experiment assessed the effect of eugenol and permethrin on nymphs locomotor activity (Fig. 2). The same doses used in the previous experiment were evaluated. Topical application of eugenol significantly hyperactivated the nymphs but only for $30 \mathrm{~min}$ (for time interval 0-10 $\mathrm{min}, F_{(2,6)}=169.8, P<0.001 ; 11-20 \mathrm{~min}$, $F_{(2,6)}=15.7, P=0.001 ; 21-30 \mathrm{~min}, F_{(2,6)}=6.22, P=$ 0.02 ) (Fig. 2a). Exposure to filter paper impregnated with permethrin did not initially affect the locomotor activity of nymphs, but during the last minutes of the assay the activity decreased significantly (for the time interval 0 10 min: $F_{(2,6)}=4.2, P=0.052 ; 11-20 \min : F_{(2,6)}=1.4$, $P=0.29 ; 21-30$ min: $F_{(2,6)}=0.37, P=0.70 ; 31-40 \mathrm{~min}$ :
$F_{(2,6)}=9.95, P=0.005 ; 41-50 \min : F_{(2,6)}=27.3, P<$ 0.001 ; 51-60 min: $F_{(2,6)}=8.83, P=0.008$ ) (Fig. 2b). This decrease in locomotor activity coincided with the appearance of spasms, convulsions, and paralysis of the third pair of legs. These are the first symptoms of intoxication with pyrethroids, which manifest before knockdown.

Next, we assessed the toxicity of permethrin (1840 $\mathrm{mg} / \mathrm{m}^{2}$ ) on nymphs simultaneously exposed to eugenol vapors released by an impregnated paper $\left(33 \mu \mathrm{g} / \mathrm{cm}^{2}\right)$ (Table 2). The KT50 values of nymphs exposed to both substances $(39.50 \mathrm{~min}$ ) was significantly lower than the values for the control group $(51.90 \mathrm{~min})(P<0.05)$. Additionally, exposure to eugenol vapors in the absence of permethrin only produced a significant increase in locomotor activity during the first $10 \mathrm{~min}$ $\left(F_{(2,9)}=10.86, P=0.001\right)$ (Fig. 3).

We then determined the mean KT50 values of nymphs injected with eugenol (2 ng/insect) and immediately exposed to a paper disc impregnated with permethrin. On average, the KT50 value of nymphs injected with eugenol was $65.30 \pm 4.80$ min while the KT50 of nymphs injected with acetone alone was $63.0 \pm 2.63 \mathrm{~min}$. The difference between these values was not significant $(P>$ 0.05 ), indicating that eugenol injection did not significantly modify the locomotor activity of nymphs compared to the control group (for the time interval $0-10$ $\min : F_{(3,36)}=1.94, P=0.14 ; 11-20 \min : F_{(3,36)}=0.04$, $P=0.99 ; 21-30 \mathrm{~min}: F_{(3,36)}=0.45, P=0.72 ; 31-40$ $\min : F_{(3,36)}=0.43, P=0.73 ; 41-50 \min : F_{(3,36)}=1.32$, $P=0.28$; 51-60 min: $F_{(3,36)}=0.90, P=0.45$ ) (Fig. 4).

Finally, we assessed the amount of permethrin picked up by nymphs treated topically with eugenol and immediately exposed to permethrin impregnated filter papers for $10 \mathrm{~min}$ (Fig. 5). Nymphs pre-treated with eugenol picked up significantly higher quantities of permethrin than individuals pre-treated with acetone alone $\left(t_{(8)}=8.17, P=0.001\right)$.

\section{Discussion}

In the present study, we report that nymphs of $T$. infestans hyperactivated by eugenol pick up more insecticide

Table 1 Knockdown time 50\% (KT50) for permethrin in T. infestans nymphs topically pre-treated with eugenol

\begin{tabular}{|c|c|c|c|c|}
\hline Pre-treatment (topical application) & $\begin{array}{l}\text { Time before exposure to a permethrin-treated } \\
\text { filter paper (min) }\end{array}$ & KT50 for permethrin (min) & $95 \% \mathrm{Cl}$ & Slope \pm SE \\
\hline Acetone & 0 & $66.75^{a}$ & $60.43-74.43$ & $8.99 \pm 1.51$ \\
\hline Eugenol $(0.1 \mu \mathrm{g} /$ insect $)$ & 0 & $46.27^{b}$ & $40.90-52.29$ & $7.40 \pm 1.15$ \\
\hline Acetone & 30 & $66.79^{a}$ & $62.16-71.94$ & $12.68 \pm 2.07$ \\
\hline Eugenol $(0.1 \mu \mathrm{g} /$ insect $)$ & 30 & $66.79^{a}$ & $61.87-72.32$ & $11.90 \pm 1.98$ \\
\hline
\end{tabular}

Abbreviations: KT50, knockdown time 50\%; 95\% CI, 95\% confidence interval; SE, standard error

Notes: Permethrin was applied as a film on filter paper $\left(1840 \mathrm{mg} / \mathrm{m}^{2}\right)$. KT50 values followed by different letters are significantly different (based on their respective $95 \% \mathrm{Cl}$ not overlapping; $P<0.05$ ) 

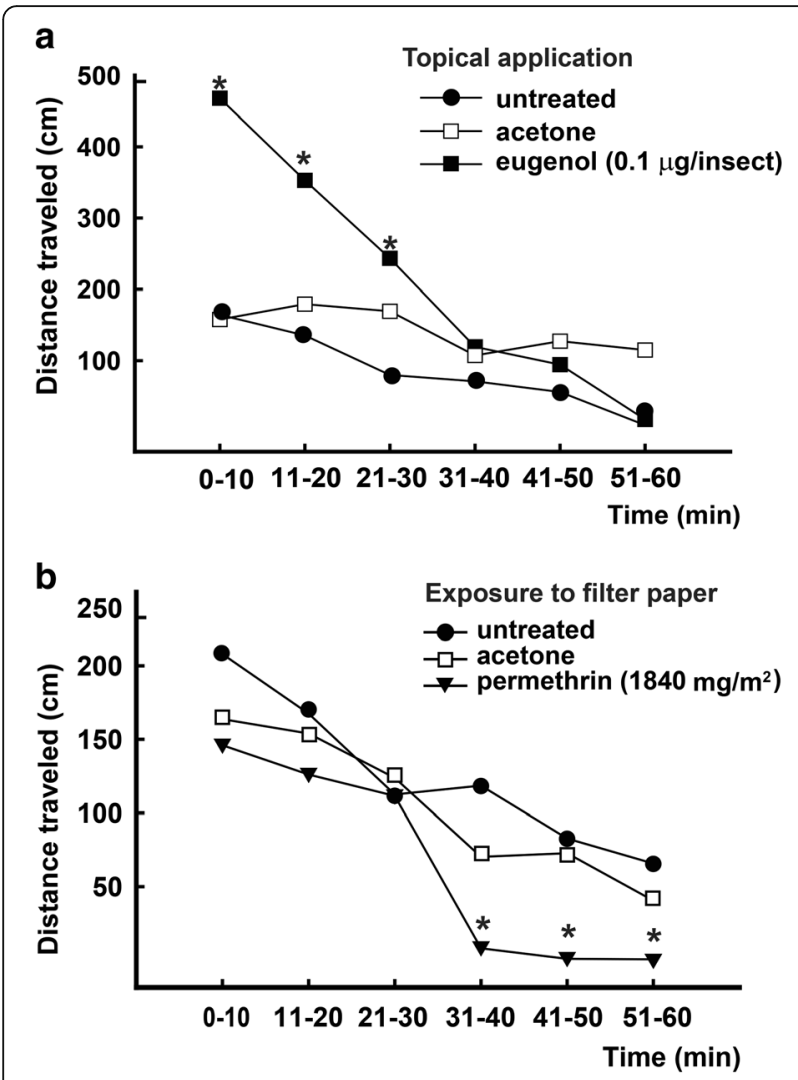

Fig. 2 Locomotor activity of T. infestans nymphs topically treated with eugenol or exposed to permethrin. a Nymphs were topically treated with acetone alone (control, empty squares) or a solution of eugenol in acetone (filled squares). $\mathbf{b}$ Nymphs were exposed to a filter paper impregnated with acetone alone (empty squares) or a solution of permethrin in acetone (filled triangles). Each symbol represents the mean of four independent replicates. Means in each time interval were analyzed using ANOVA. Symbols marked with an asterisk are significantly different from both untreated and acetone controls $(P<0.05)$

from a permethrin-treated surface, thus becoming intoxicated faster than non-hyperactivated nymphs.

We quantified knockdown values produced by permethrin in four different situations: (a.i) immediately after a topical application of eugenol; (a.ii) $30 \mathrm{~min}$ after a topical application of eugenol; (b) simultaneously with the exposure to eugenol vapors; and (c) immediately after eugenol injection. The KT50 values of permethrin

Table 2 Knockdown time 50\% (KT50) for permethrin in T. infestans nymphs exposed simultaneously to eugenol vapor

\begin{tabular}{llll}
\hline Simultaneous exposure to: & KT50 (min) & $95 \% \mathrm{Cl}$ & Slope \pm SE \\
\hline Acetone & $51.90^{\mathrm{a}}$ & $46.9-56.7$ & $8.70 \pm 1.39$ \\
Eugenol $\left(33 \mu \mathrm{g} / \mathrm{cm}^{2}\right)$ & $39.50^{\mathrm{b}}$ & $34.9-44.8$ & $6.30 \pm 0.89$
\end{tabular}

Abbreviations: KT50, knockdown time 50\%; 95\% Cl, 95\% confidence interval Notes: Permethrin was applied as a film on filter paper $\left(1840 \mathrm{mg} / \mathrm{m}^{2}\right)$. KT50 values followed by different letters are significantly different (based on their respective $95 \% \mathrm{Cl}$ not overlapping; $P<0.05$ )

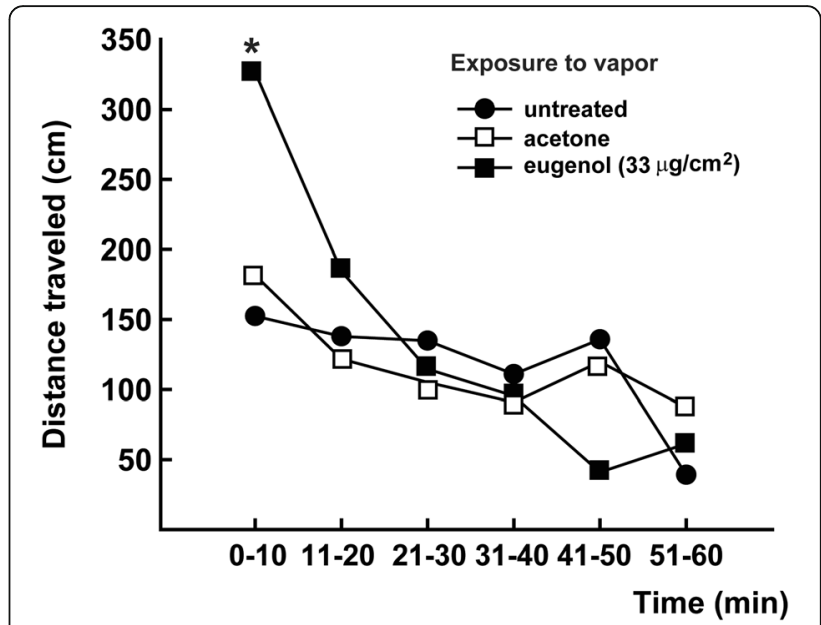

Fig. 3 Locomotor activity of T. infestans nymphs exposed to vapors of eugenol. Nymphs were exposed to a filter paper impregnated with acetone (control, empty squares) or a solution of eugenol in acetone (filled squares). Each symbol represents the mean of four independent replicates. Means in each time interval were analyzed using ANOVA. Symbols marked with an asterisk are significantly different from both untreated and acetone controls $(P<0.05)$

were significantly lower than the controls in situations (a.i) and (b). Moreover, when eugenol was applied in the absence of permethrin, it only produced hyperactivity in those same two situations.

Locomotor activity is a complex characteristic that is directly or indirectly involved in almost all the activities of an insect and is regulated by a neurophysiological mechanism [30]. It has a very important role in survival and depends on both internal (age, hormonal state) and

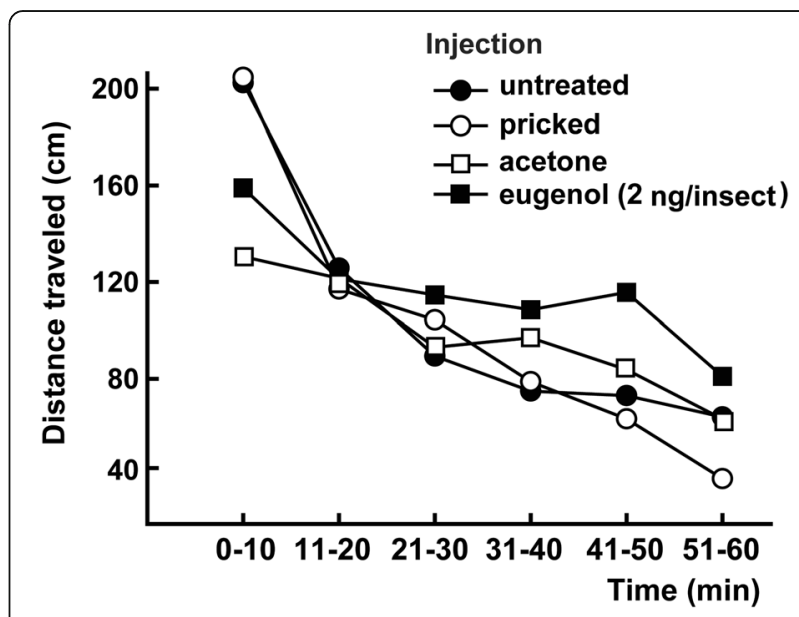

Fig. 4 Locomotor activity of $T$. infestans nymphs injected with eugenol. Nymphs were injected with acetone alone (control, empty squares) or a solution of eugenol in acetone (filled squares). Each symbol represents the mean of ten independent repetitions. Means in each time interval were analyzed using ANOVA. No significant differences were detected in any case $(P>0.05)$ 


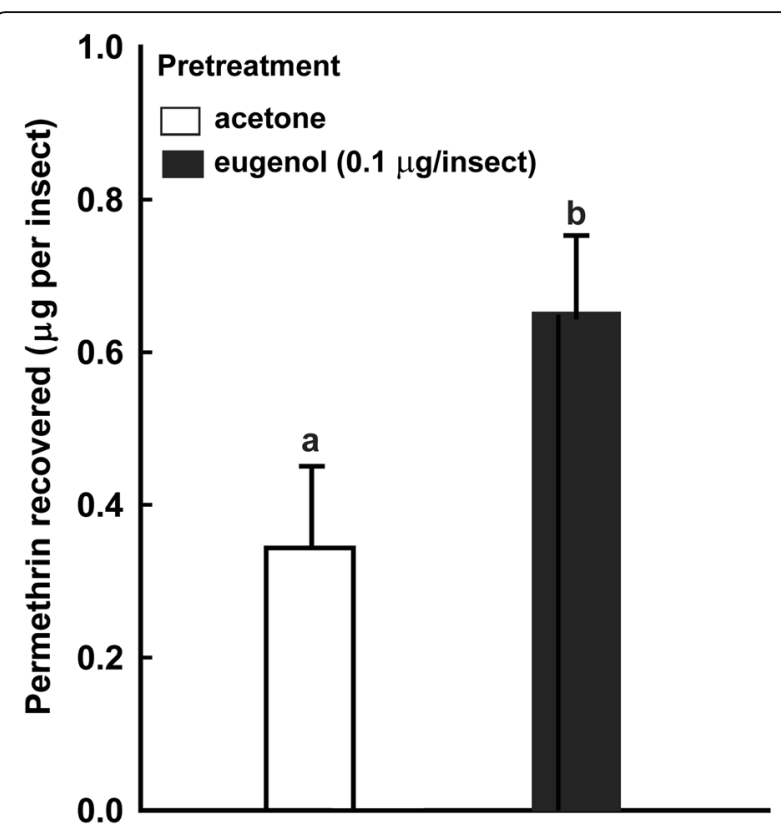

Fig. 5 Permethrin picked-up by hyperactivated $T$. infestans from an impregnated filter paper. Nymphs were topically pre-treated with acetone alone (empty bar) or a solution of eugenol in acetone (filled bar), then exposed to a filter paper treated with permethrin (1840 $\mathrm{mg} / \mathrm{m}^{2}$ ). Each bar represents the mean of five independent replicates. Vertical lines represent the SE. Bars marked with different letters are significantly different (Student's t-test, $P<0.05$ )

external (presence or absence of predators and conspecifics) factors [31-34]. Of particular interest is the recent discovery that infection with $T$. cruzi increases the locomotor activity of $R$. prolixus, whereas infection with $T$. rangeli causes a decrease [35].

Exposure to DDT and other insecticides increases the locomotor activity of insects [36-38]. Nymphs of $T$. infestans resistant to deltamethrin showed a reduced sensitivity to the hyperactivity produced by this insecticide when compared to deltamethrin-susceptible individuals [39]. Hyperactivity was also observed in insects exposed to components of essential oils [10], but it was only quite recently that this effect was quantified exposing $T$. infestans and $R$. prolixus to alcoholic monoterpenes $[8,9]$.

In the present study, the effect of eugenol on the locomotor activity of the nymphs varied considerably according to the form of administration. Topical application produced the highest effect, followed by exposure to vapors, whereas eugenol injection caused no modification in nymph locomotor activity.

The amount of compound that reaches an insect depends strongly on the type of exposure [40]. For example, insects exposed to an insecticidal film mainly pick up the compound by their legs, whereas topical application generates a more extensive distribution on the body cuticle [41].
In the present study, nymphs treated topically received a larger amount of eugenol than those exposed to vapors. Therefore, the difference observed in the effect on locomotor activity could be due to the fact that a higher dose produces a greater effect.

Why did eugenol fail to produce hyperactivity when injected? The dose applied ( $2 \mathrm{ng}$ of eugenol/insect) might have been too low to modify the nymphs' locomotor activity. In fact, hyperactivity by eugenol and other monoterpenes is dose-dependent in T. infestans and $R$. prolixus $[8,9]$. We were unable to test higher doses because they rapidly produced symptoms of intoxication (lateral walking, proboscis extension, leg tremors). Applying a substance that hyperactivates the nymphs at a dose that is much lower than the threshold producing intoxication symptoms could help solve this issue.

On the other hand, the effect of eugenol on hyperactivity could be induced via the neurons of sensory structures on the cuticle that react to different environmental stimuli. If this is true, stimulation would not occur when the monoterpene is injected into the hemolymph. The very rapid manifestation of hyperactivity when nymphs were exposed to eugenol vapors (Fig. 4) provides evidence that supports this explanation.

The mode of action of most monoterpenes remains unknown. Eugenol is one of the few exceptions, as evidence suggests that its primary site of action is the octopaminergic receptor [10]. The octopaminergic system is widely distributed throughout the central and peripheral nervous systems of invertebrates, where it participates in many physiological and behavioral aspects [42]. Within the context of the present study, it is important to note that the octopaminergic system is involved in the initiation and maintenance of rhythmic behaviors such as walking [4345]. Based upon this knowledge, an interaction between eugenol and octopaminergic receptors could explain the hyperactivity observed in our experiments.

After demonstrating that hyperactivated nymphs become intoxicated more rapidly than the non-hyperactivated ones when exposed to a permethrin-treated surface, we quantified the amount of insecticide permethrin picked up in both situations. For this we adapted two protocols, one used for extracting dieldrin picked up by mosquitoes exposed to a surface treated with this insecticide [27], and another used to quantify permethrin and other insecticides in water samples [28]. This way, we managed to detect minute quantities of permethrin picked up by the nymphs exposed to treated filter papers. Our results showed that the nymphs hyperactivated by eugenol picked up more permethrin than the non-hyperactivated ones.

As mentioned in Background, a similar result was observed by other authors working with two strains of $H$. virescens, one susceptible and the other resistant to 
permethrin [24]. When exposed to a permethrin-treated surface, larvae from the resistant strain were less active and picked up less insecticide, than larvae from the susceptible strain. This behavioral response was considered partially responsible for the resistance to permethrin.

In summary, here we have gathered a significant amount of evidence that support our hypothesis: eugenol-hyperactivated nymphs of $T$. infestans pick up more insecticide, and then become intoxicated faster, than non-hyperactivated nymphs when exposed to a permethrin-treated surface.

Future studies should investigate the effects of other monoterpenes as possible enhancers of the toxicity of different insecticides on triatomines. Mixtures of monoterpenes should also be evaluated, to establish whether synergistic interactions occur. The application of mixtures of monoterpenes and conventional insecticides under field conditions is a possibility that is worth exploring, since hyperactivity could increase the exposure to recently applied insecticides, increasing the efficacy of control. Another issue to be investigated is the effect of eugenol on the locomotor activity of both trypanosomes-infected and resistant to pyrethroids $T$. infestans. These studies could elucidate for the physiological basis of the hyperactivity induced by insecticides in insects.

\section{Conclusion}

Results from toxicological, behavioral and analytical assays performed in this work support the hypothesis that eugenol-hyperactivated nymphs of $T$. infestans pick up more insecticide, and then become intoxicated faster, than non-hyperactivated nymphs when exposed to a permethrin-treated surface.

\section{Abbreviations \\ 95\% Cl: 95\% confidence interval; DT: Distance traveled; GC-MS: Gas chomatography - mass spectrometry; KT50: Knockdown time 50\%}

\section{Acknowledgements}

AL and RAA are members of the Carrera del Investigador Científico del Consejo Nacional de Investigaciones Científicas y Técnicas of Argentina (CONICET). MMNR is a fellowship holder of the CONICET for her doctoral studies at Universidad de San Martín. We thank Catriona Kirkwood for translating the manuscript into English.

\section{Funding}

This work was funded by the Agencia Nacional de Promoción Científica y Tecnológica, Argentina (PICT 2012/1471 to ENZ).

\section{Availability of data and materials}

All data generated and/or analyzed during this study are included in this published article.

\section{Authors' contributions}

MMNR conceived, designed and performed the experiments, analyzed the data, prepared figures and tables, and wrote and reviewed drafts of the paper. AL conceived, designed and performed the experiments, and wrote and reviewed drafts of the paper. ENZ and RAA conceived and designed the experiments, and wrote and reviewed drafts of the paper. All authors read and approved the final manuscript.

\section{Ethics approval}

No human participants, human data or human tissue were used in the present study. Insects were fed on pigeon blood once per week according to a protocol approved by the Institutional Animal Care and Use Committee of CIPEIN (IACUC/CICUAL 1531/13).

\section{Consent for publication}

Not applicable.

\section{Competing interests}

The authors declare that they have no competing interests.

\section{Publisher's Note}

Springer Nature remains neutral with regard to jurisdictional claims in published maps and institutional affiliations.

Received: 11 May 2018 Accepted: 10 October 2018

Published online: 03 November 2018

\section{References}

1. Kamatou GP, Vermaak I, Viljoen AM. Eugenol - from the remote Maluku islands to the international market place: a review of a remarkable and versatile molecule. Molecules. 2012;17:6953-81.

2. Barceloux DG. Medical toxicology of natural substances: Foods, fungi, medicinal herbs, plants, and venomous animals. Hoboken: John Wiley \& Sons; 2008.

3. Obeng-Ofori $D$, Reichmuth C. Bioactivity of eugenol, a major component of essential oil of Ocimum suave (Wild.) against four species of stored-product Coleoptera. Int J Pest Manage. 1997;43:89-94.

4. Huang H, Ho SH, Lee HC, Yap IL. Insecticidal properties of eugenol, isoeugenol and methyleugenol and their effects on nutrition of Sitophilus zeamais Motsch. (Coleoptera: Curculionidae) and Tribolium castaneum (Herbst) (Coleoptera: Tenebrionidae). J Stored Prod Res. 2002;38:403-12.

5. Waliwitiya R, Kennedy CJ, Lowenberger CA. Larvicidal and ovipositionaltering activity of monoterpenoids, trans-anithole and rosemary oil to the yellow fever mosquito Aedes aegypti (Diptera: Culicidae). Pest Manag Sci. 2009;65:241-8.

6. Tabanca N, Bernier UR, Ali A, Wang M, Demirci B, Blythe EK, et al. Bioassayguided investigation of two Monarda essential oils as repellents of yellow fever mosquito Aedes aegypti. J Agr Food Chem. 2013;61:8573-80.

7. Ali A, Cantrell CL, Khan KA. New in vitro bioassay system for the discovery and quantitative evaluation of mosquito repellents. J Med Entomol. 2017;54: 1328-36.

8. Moretti A, Zerba EN, Alzogaray RA. Behavioral and toxicological responses of Rhodnius prolixus and Triatoma infestans (Hemiptera: Reduviidae) to ten monoterpene alcohols. J Med Entomol. 2013;50:1046-54

9. Moretti AN, Seccacini EA, Zerba EN, Canale D, Alzogaray RA. The botanical monoterpenes linalool and eugenol flush-out nymphs of Triatoma infestans. J Med Entomol. 2017:54:1293-8.

10. Enan EE. Insecticidal activity of essential oils: octopaminergic sites of action. Comp Biochem Phys C. 2001;130:325-37.

11. Wilkinson CF. Insecticide Interaction: Insecticide Biochemistry and Physiology. New York: Plenum Press; 1976.

12. Savelev S, Okello E, Perry NSL, Wilkins RM, Perry EK. Synergistic and antagonistic interactions of anticholinesterase terpenoids in Salvia lavandula efolia essential oil. Pharmacol Biochem Behav. 2003;75:661-8.

13. Ntalli NG, Ferrari F, Giannakou I, Menkissoglu-Spiroudi U. Synergistic and antagonistic interactions of terpenes against Meloidogyne incognita and the nematicidal activity of essential oils from seven plants indigenous to Greece. Pest Manag Sci. 2011;67:341-51.

14. Tak JH, Jovel E, Isman MB. Comparative and synergistic activity of Rosmarinus officinalis L. essential oil constituents against the larvae and anovarian cell line of the cabbage looper, Trichoplusia ni (Lepidoptera: Noctuidae). Pest Manag Sci. 2016;72:474-80.

15. Pavela R. Acute, synergistic and antagonistic effects of some aromatic compounds on the Spodoptera littoralis Boisd. (Lep., Noctuidae) larvae. Ind Crop Prod. 2014;60:247-58.

16. Cedergreen N. Quantifying synergy: a systematic review of mixture toxicity studies within environmental toxicology. PLoS One. 2014;9:e96580. 
17. Passreiter CM, Wilson Andersen JR, Isman MB. Metabolism of thymol and trans-anethole in larvae of Spodoptera litura and Trichoplusia ni (Lepidoptera: Noctuidae). J Agr Food Chem. 2004;52:2549-51.

18. Taylor WG, Fields PG, Sutherland DH. Insecticidal components from field pea extracts: soyasaponins and lysolecithins. J Agric Food Chem. 2004;52:7484-90.

19. Fields PG, Woods S, Taylor WG. Triterpenoid saponins synergize insecticidal pea peptides: effect on feeding and survival of Sitophilus oryzae (Coleoptera: Curculionidae). Can Entomol. 2010;142:501-12.

20. Tak JK, Isman MB. Enhanced cuticular penetration as the mechanism of synergy for the major constituents of thyme essential oil in the cabbage looper, Trichoplusia ni. Ind Crop Prod. 2017;101:29-35.

21. Dickens J. Green leaf volatiles enhance aggregation pheromone of boll weevil, Anthonomus grandis. Entomol Exp Appl. 1989;52:191-203.

22. Hallett RH, Oehlschlager AC, Borden JH. Pheromone trapping protocols for the Asian palm weevil, Rhynchophorus ferrugineus (Coleoptera: Curculionidae). Int J Pest Manage. 1999;45:231-7.

23. Reinecke A, Hilker M. Plant semiochemicals - Perception and behavioural responses by insects. Annu Rev Plant Biol. 2014;47:115-54.

24. Sparks TC, Lockwood JA, Byford RL, Graves JB, Leonard BR. The role of behavior in insecticide resistance. Pestic Sci. 1989;26:383-99.

25. Casabé N, Melgar F, Wood EJ, Zerba EN. Insecticidal activity of pyrethroids against Triatoma infestans. Int J Trop Insect Sci. 1988;9:233-6.

26. Noldus. Software Ethovision XT 10.0. Leesburg: Noldus Information Technology Inc; 2013.

27. Pennell JT, Miskus R, Craig R. The use of gas chromatography for the quantitative determination of micro-amounts of insecticide picked up by mosquitos. Bull World Health Organ. 1964;30:91-5.

28. Pinheiro AS, Rocha GO, Andrade JB. A SDME/GC-MS methodology for determination of organophosphate and pyrethroid pesticides in water. Microchem J. 2001;99:303-8.

29. Throne JE, Weaver DK, Chew V, Baker JE. Probit analysis of correlated data: multiple observations over time at one concentration. J Econ Entomol. 1995;88:1510-2

30. Klowden MJ. Physiological Systems in Insects. Idaho: Academic Press; 2007

31. Hoffmann AA. The influence of age and experience with conspecifics on territorial behavior in Drosophila melanogaster. J Insect Behav. 1990;3:1-12.

32. Rakshit K, Wambua R, Giebultowicz TM, Giebultowicz JM. Effects of exercise on circadian rhythms and mobility in aging Drosophila melanogaster. Exp Gerontol. 2013;48:1260-5.

33. Van Der Bijl W, Thyselius M, Kotrschal A, Kolm N. Brain size affects the behavioural response to predators in female guppies (Poecilia reticulata). $P$ Roy Soc B-Bio Sci. 2015;282:20151132.

34. Pflüger HJ, Duch C. Dynamic neural control of insect muscle metabolism related to motor behavior. Physiol. 2011;26:293-303.

35. Marliere NP, Latorre-Estivalis JM, Lorenzo MG, Carrasco D, Alves-Silva J, de Oliveira RJ, et al. Trypanosomes modify the behavior of their insect hosts: effects on locomotion and on the expression of a related gene. PLoS Negl Trop Dis. 2015;9:e0003973.

36. Gammon DW. Neural effects of allethrin on the free walking cockroach Periplaneta americana: an investigation using defined doses at 15 and $32{ }^{\circ} \mathrm{C}$. Pestic Sci. 1978;9:79-81.

37. Toth SJ, Sparks TC. Effect of temperature on toxicity and knockdown activity of cis-permethrin, esfenvalerate, and lambda-cyhalothrin in the cabbage looper (Lepidoptera: Noctuidae). J Econ Entomol. 1990;83:342-6.

38. Alzogaray RA, Fontán A, Zerba EN. Evaluation of hyperactivity produced by pyrethroid treatment on third instar nymphs of Triatoma infestans (Hemiptera: Reduviidae). Arch Insect Biochem. 1997;35:323-33.

39. Sfara V, Zerba EN, Alzogaray RA. Toxicity of pyrethroids and repellency of diethyltoluamide in two deltamethrin resistant colonies of Triatoma infestans Klug, 1834 (Hemiptera: Reduviidae). Mem Inst Oswaldo Cruz. 2006; 101:89-94.

40. Matsumura F. Toxicology of Insecticides. 2nd ed. Berlin: Springer Science \& Business Media; 2012.

41. Miller TP, Gold RE, Ball HJ. Tissue analysis and hemolymph translocation of $\left[{ }^{14} \mathrm{C}\right]$ chlorpyrifos sorbed from treated surfaces by American cockroaches. Pestic Biochem Phys. 1983;20:19-24.

42. Farooqui T. Review of octopamine in insect nervous systems. Insect Physiol. 2012;4:1-17.

43. Yang NW, Li AL, Wan Liu FH, Johnson D. Effects of plant essential oils on immature and adult sweetpotato whitefly, Bemisia tabaci biotype B. Crop Prot. 2010;29:1200-7.
44. Saraswati S, Fox LE, Soll DR, Wu CF. Tyramine and octopamine have opposite effects on the locomotion of Drosophila larvae. J Neurobiol. 2004; 58:425-41.

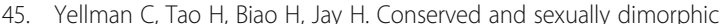
behavioral responses to biogenic amines in decapitated Drosophila. Proc Natl Acad Sci USA. 1997:94:4131-6.
Ready to submit your research? Choose BMC and benefit from:

- fast, convenient online submission

- thorough peer review by experienced researchers in your field

- rapid publication on acceptance

- support for research data, including large and complex data types

- gold Open Access which fosters wider collaboration and increased citations

- maximum visibility for your research: over $100 \mathrm{M}$ website views per year

At BMC, research is always in progress.

Learn more biomedcentral.com/submissions 